\title{
The Effect of Thermal Shocking with Nitrogen Gas on the Porosities, Permeabilities, and Rock Mechanical Properties of Unconventional Reservoirs
}

\author{
Khalid Elwegaa * (D) and Hossein Emadi $(\mathbb{D})$ \\ Bob L. Herd Department of Petroleum Engineering, Texas Tech University, 2500 Broadway, \\ Lubbock, TX 79409, USA; h.emadibaladehi@ttu.edu \\ * Correspondence: khalid.elwegaa@ttu.edu; Tel.: +1-720-939-7769
}

Received: 19 June 2018; Accepted: 13 August 2018; Published: 15 August 2018

\begin{abstract}
Cryogenic fracturing is a type of thermal shocking in which a cold liquid or gas is injected into a hot formation to create fractures. Research has shown that like traditional hydraulic fracturing, cryogenic fracturing could improve oil/gas recovery from unconventional reservoirs. Research has also shown, though, that, unlike traditional hydraulic fracturing, which uses water-based fluids, cryogenic fracturing limits and can even heal damage that is near the wellbore. Previous studies on thermal shocking, however, have generally examined only a few parameters at a time. To provide a more complete overview of the process, this study examines the effects of thermal shocking with low-temperature nitrogen gas on the porosities, permeabilities, and rock mechanical properties of unconventional reservoirs. Three cycles of thermal shocking were applied to a core sample and an outcrop sample from an unconventional reservoir. Each sample was heated at $82{ }^{\circ} \mathrm{C}$ for $1 \mathrm{~h}$, and then nitrogen at $-18{ }^{\circ} \mathrm{C}$ was injected at $6.89 \mathrm{MPa}$ for $5 \mathrm{~min}$. The porosities and permeabilities of the cores and the velocities at which ultrasonic waves travelled through them were measured both before and after each thermal shock. The results strongly suggest that the thermal shocking produced cracks. The porosity increased by between $1.34 \%$ and $14.3 \%$, the permeability increased by between $17.4 \%$ and $920 \%$, and the average P-wave velocity decreased by up to $100 \mathrm{~m} / \mathrm{s}$. From the reduction in P-wave velocity, it was determined that the brittleness ratio increased by between 2 and 4 and the fracability index increased by between 0.2 and 0.8 .
\end{abstract}

Keywords: thermal shock; cryogenic fracturing; unconventional reservoirs; nitrogen gas; porosity; permeability; rock mechanical properties; P-wave velocity; brittleness ratio; fracability index

\section{Introduction}

Hydraulic fracturing is a major technique to produce economically from unconventional oil and gas reservoirs. Numerous researches have been conducted in order to optimize hydraulic fracturing operation to maximize oil and gas production from unconventional reservoirs [1-5]. Connecting hydraulic fractures with existing natural fracture network in formation matrix enhances the efficiency of stimulation process and increases resultant hydrocarbon production rate. Unlike the conventional hydraulic fracturing process, thermal Shock is a new technique to initiate fractures and to connect the existing fractures and fissures in the rock matrix by altering the effective stresses around the wellbore or at the existing fractures surface areas.

Researchers have been investigating thermal shock technique since the 1970s. Using analytical and experimental methods, Finnie et al. [6] evaluated thermal cracking resulting from cooling with liquid nitrogen. In that experiment, they injected liquid nitrogen into $5 \mathrm{~cm}$ long by $1 \mathrm{~cm}$ diameter central holes in $10 \mathrm{~cm}$ cubes of Solnhofen limestone. They concluded that rapidly decreasing the 
temperature at the surface creates tensile stresses that initiate and propagate cracks in the rock. Geyer and Nemat-Nasser [7] thermally induced parallel edge cracks in a half-plane consisting of brittle material. A glass plate was heated to a uniform temperature and then exposed to a liquid bath that is cooled by dry ice. When the edge of the plate came into contact with the bath of cold liquid, the edge became a thermal boundary layer for the glass as a whole. The boundary layer thermally contracted, producing tensile cracks. These cracks propagated perpendicularly to the cooled edge. Grundmann et al. [8] discussed the successful field application of cryogenic fracturing. In this study, liquid nitrogen was used to stimulate a well drilled in the unconventional reservoir (Devonian shale) in Eastern Kentucky. They concluded that more tests are required to improve the fracture-flow conductivity while using thermal shock. Kim and Kemeny [9] conducted laboratory tests to study whether rapid cooling damages rock or not. Granite and diabase with ore veins samples were tested in this study. The rock was slowly heated to $100{ }^{\circ} \mathrm{C}$ and then cooled it rapidly. The results showed that crack growth caused by thermal shock occurred in some rock types. They concluded that rapid cooling of a rock surface results in a non-uniform temperature distribution, which builds considerable thermal stresses. These stresses are due to tension on the surface of the rock and compression in center of its body. These stresses may grow the present crack network or heal the cracks depending on the type of rock. Kocabas [10] presented a transient analytical model to study the effect of a non-isothermal water injection on the temperature and stress distribution around the wellbore. The results showed that the thermoelastic changes in the cooled zone could highly affect the surrounding stress fields. He reported that this phenomenon may induce new fracture or propagate the existing ones. Tarasovs and Ghassemi [11] developed a simulation model to examine the process of thermal stimulation. The results indicated that the secondary cracks were mainly determined by the temperature distribution in a geothermal reservoir. Kumar and Gutierrez [12] also developed a two-dimensional (2D) transient heat flow model to estimate the thermal induced effects on fracture geometry. A cold fluid was injected into hot rocks and caused the rocks surrounding the fracture to become relatively cool. This resulted in a change in tensile stresses and an expansion of the fracture volume. Tran et al. [13] used a 2D-plain-strain simulation model to study effects of the temperature difference between an injected cold fluid and a hot reservoir model on crack initiation. The results demonstrated that thermal stresses are the dominant cause of secondary fractures and that the initiation and propagation of secondary cracks is possible, even with the short-term injection of hydraulic fracture fluid.

In the last few years, several experimental works have been conducted to study the cryogenic fracturing technology and its applications. Alqahtani [14] presented Cryogenic fracturing experimental tests. The tests were carried out on concrete, tight sandstone, and Niobrara shale samples while using liquid nitrogen. The results showed that cryogenic fracturing has not only a positive effect on rock permeability especially shale samples, but also has almost no formation damage potential. Zhao et al. [15] conducted rock mechanical properties test under cryogenic conditions (rock samples were subjected to liquid nitrogen). The results showed that both shear strength and tensile strength of the rock samples significantly decreased. They concluded that the thermal shock that was caused by the cryogenic treatment could create new microfractures and extend the existing microfractures, and consequently enhance the production capacity of the well. Yao et al. [16] also conducted laboratory cryogenic fracturing experiments to investigate the ability of enhancing the permeability of synthetic rock samples (concrete). 20.3-cm rock cubic samples were used in these experiments. Eight tiny thermocouples were embedded in their diagonals to monitor the temperature change during the tests. The samples were under triaxial stresses and in the meantime, liquid nitrogen was circulated into the samples through 15.24-cm-deep holes. The results showed that the permeability of the affected area was increased.

Cryogenic fracturing is a stimulation technology that uses cryogenic fluids like liquid nitrogen to fracture unconventional oil and gas reservoirs and it reduces the formation damage, as it is a waterless technology [17-19]. Smith [20] also reported that using the Earth's geothermal energy to 
warm cryogenic flood fluids injected into unconventional reservoirs causes an increase in reservoir pressure and this rise in pressure results in the production of fluids from the reservoirs.

Thermal Shock is a technique in which a fluid at a low temperature is injected into a hot reservoir. Temperature difference between the injected fluid and the wall of the main fracture of the wellbore results in an increase in tensile stress [21-25] and a decrease in the maximum horizontal effective stress (stress in the direction parallel to the main fracture in case of transvers fracture). If the decrease in maximum horizontal effective stress and the increase in tensile stress are adequate, a secondary crack is initiated. In addition to that, applying thermal shock to rock surface and existing hydraulic fractures will alter the rock mechanical properties (Young's modulus and Poisson's ratio) and it creates a secondary fracture network in rock body. This change in rock mechanical properties results in rock brittleness alteration and thus the possible propagation of existing fracture network in rock matrix.

In contrast, the thermal shock technique can cause crack healing instead of crack growth. In crack healing, the crack density of the rock decreases slightly [26]. When a rock sample is heated slowly, for example, its thermal expansion can fill cracks and voids. Overall healing is expected when the amount of crack healing in the central parts of a rock sample (due to slow heating) exceeds the crack growth near the surface of the sample (due to rapid cooling) [9].

Factors affecting success of thermal shock technique are listed below $[9,15,26-29]$ :

- Natural fracture network: Existence of natural fracture in a rock decreases the rock tensile strength and assists creating new fractures.

- Rapid thermal load: Applying rapid thermal load results in a steep temperature gradient between the body and the surface of rock and helps to create fractures.

- Low rock thermal conductivity and high thermal expansion coefficient. These are both rock intrinsic properties.

- Brittleness of rock sample: There is a direct relationship between the brittleness of rock sample and successfully creating fractures while using thermal shock technique.

- Fracture toughness: There is an inverse relationship between fracture toughness and successfully creating fractures while using thermal shock technique.

In this study, impacts of thermal shock on porosity, permeability, and mechanical properties of shale rock were examined using two core samples. Three cycles of thermal shock were conducted using cold nitrogen gas on each core sample and porosity, permeability, and acoustic measurement tests were performed on each core sample prior and after completing each cycle of thermal shock.

\section{Experimental Work}

\subsection{Core Preparation}

Two core samples were used in this experimental study. One core is from Eagle Ford outcrop (EF\#5), and the other one is a real core that was collected from a shale formation at depth of $2956 \mathrm{~m}$ at Anderson county, Texas (SH\#5) (Figure 1 and Table 1).

Table 1. Core samples dimensions, bulk volume and dry bulk density.

\begin{tabular}{ccccc}
\hline Core Name & Length & Diameter & \begin{tabular}{c} 
Bulk Volume \\
\cline { 2 - 3 }$\left(\mathbf{c m}^{\mathbf{3}}\right)$
\end{tabular} & $\begin{array}{c}\text { Dry Bulk } \\
\text { Density } \mathbf{( g / \mathbf { c m } ^ { 3 } )}\end{array}$ \\
\hline EF\#5 & $\mathbf{c m}$ & $\mathbf{c m}$ & & \\
SH\#5 & 5.12 & 3.81 & 58.42 & 2.18 \\
\hline
\end{tabular}




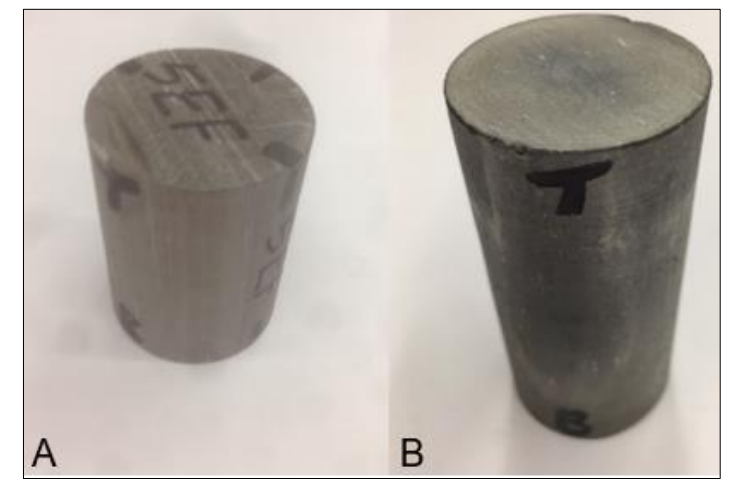

Figure 1. (A) Core plug from Eagle Ford outcrop; and (B) real core plug from shale formation at Anderson County, Texas.

The samples were placed in a vacuum oven dryer and heated to $43{ }^{\circ} \mathrm{C}$ to evaporate all free hydrocarbons and water present in the pore spaces. This process lasted for about $48 \mathrm{~h}$, until the dry core samples reached constant weights.

\subsection{Porosity Measurement}

A gas porosimeter with the ability of vacuuming was used to measure the core samples' effective porosity while using helium. The following formula was used to calculate effective porosity of the core samples.

$$
\varnothing_{e}=\frac{V_{B M}-V_{S}}{V_{B M}} \times 100
$$

where $\varnothing_{e}$ is the effective porosity; $V_{B M}$ is the measured bulk volume of the core sample; and $V_{S}$ is the grain volume of the core sample. The core samples porosity was measured both prior to and after performing each thermal shock cycle.

\subsection{Permeability Measurement}

Shale formations have ultra-low permeabilities that cannot be measured while using the conventional steady state method. A complex transient method, which was developed by Boitnott [30], was used in this research to measure the core samples permeabilities. NER AutoLab 1500 (New England Research, Inc., White River Junction, VT, USA) was used to perform the permeability measurement tests. The permeabilities of the two core samples EF\#5 and SH\#5 were measured before applying thermal shock and then after each cycle of thermal shock to monitor the effect of cold nitrogen on permeability.

The AutoLab 1500 (Figure 2) is a complete laboratory system with three integrated components:

- A high-pressure vessel with a base plug to hold a core sample and three pressure intensifiers to apply pore pressure, confining pressure and axial load on the core sample.

- An electronic console to accurately control the pressures (pore pressure, confining pressure and axial load) using the panel mode. Additionally, the electronic console is utilized to adjust and amplify signals from the transducers to measure the following: axial load, pressure, displacement, temperature, and velocity.

- AutoLab acquisition system that controls the experiment, acquires and processes the data after completing the experiment.

Permeability Test Procedure:

- After sample jacketing and preparation (Figure 3), the sample was inserted in the high-pressure (HP) vessel and secured. 
- A confining pressure was applied manually using a panel mode on the electronic console up to 3.45 MPa.

- The vent valve was opened to load the pore pressure intensifier with gas.

- On the data acquisition system, permeability experiment was selected and the sample information was loaded to the system.

- A computer mode was used instead of the panel mode to easily control both confining and pore pressures.

- The pore pressure valve was opened and then the gas flew inside the sample from the upstream side.

- Using the data acquisition system to monitor the pore pressure at both ends of the sample (upstream and downstream). After both pressures became almost equal, permeability measurement starts and the system measures the permeability at the conditions, as shown in Table 2.

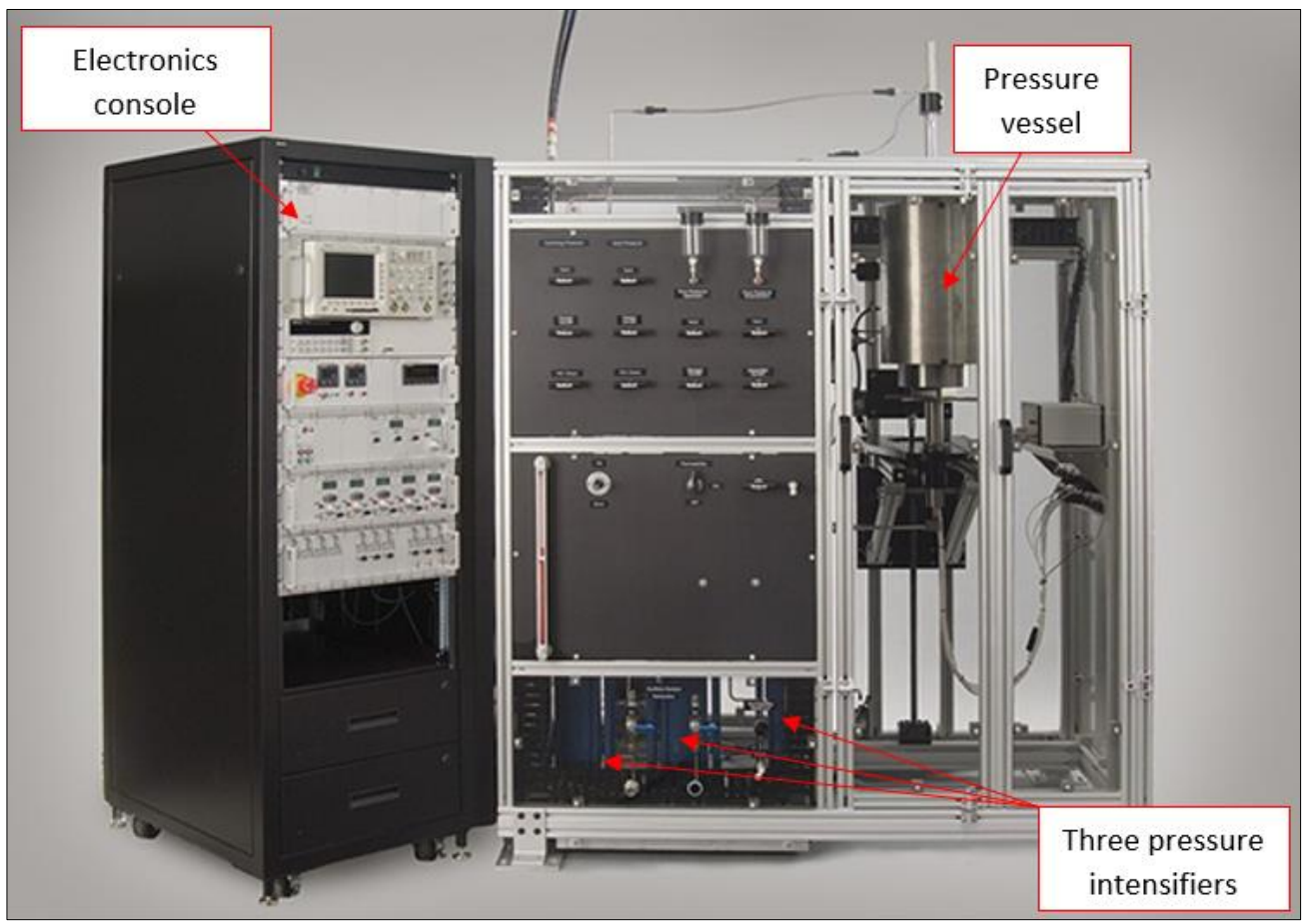

Figure 2. New Research England (NER) AutoLab 1500 system for permeability and ultrasonic velocity measurements.

Table 2. Parameters selected for permeability measurement.

\begin{tabular}{ccccc}
\hline Method & $\begin{array}{c}\text { Confining } \\
\text { Pressure (MPa) }\end{array}$ & $\begin{array}{c}\text { Pore Pressure } \\
(\mathbf{M P a})\end{array}$ & $\begin{array}{c}\text { Injected } \\
\text { Gas }\end{array}$ & $\begin{array}{c}\text { Core Holder } \\
\text { Temperature }\left({ }^{\circ} \mathbf{C}\right)\end{array}$ \\
\hline $\begin{array}{c}\text { Complex transient } \\
\text { (multi-pulse) }\end{array}$ & 13.8 & 6.89 & Helium & 21 \\
\hline
\end{tabular}




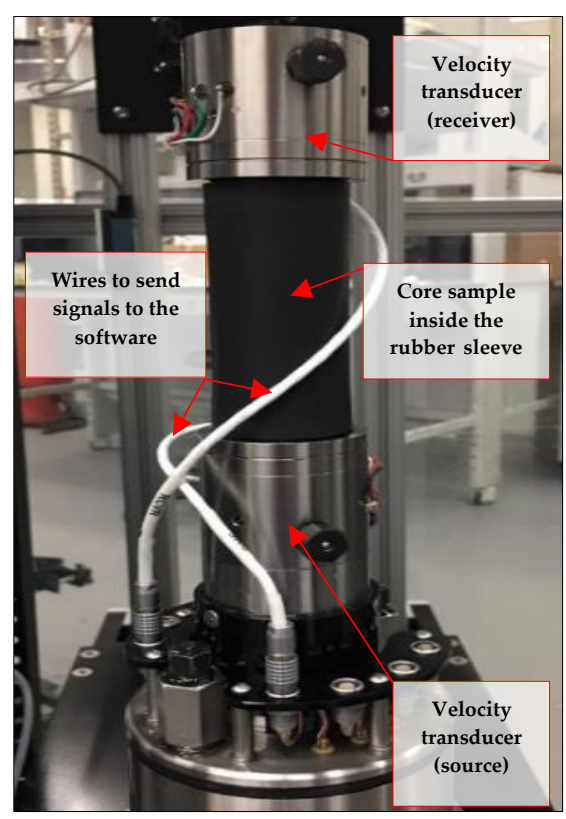

Figure 3. Core sample assembly is ready for axial velocity measurement.

\subsection{Axial Velocity Measurement}

NER's AutoLab 1500 system also provides ultrasonic velocity measurements. The AutoLab 1500 machine can measure the compressional ( $\mathrm{P}$-wave) and the shear $\left(\mathrm{S}_{1}\right.$ and $\mathrm{S}_{2}$ waves) while using two velocity ultrasonic transducers (receiver and transmitter). This velocity measurement is called the axial velocity test because the source transducer is placed at the bottom of the core sample whereas the receiver is placed at the top of the core sample.

Both dynamic Young's module and Poisson's ratio can be determined from the axial velocity test, which are both very important parameters to identify any induced fractures due to the cold nitrogen injection. The axial velocity measurement was conducted before and after each cycle of thermal shock to study the effect of thermal shock on the compressional velocity $\left(V_{\mathrm{p}}\right)$, dynamic Young's module, and Poisson's ratio.

After that, rock brittleness was calculated and analyzed for both EF\#5 and SH\#5 using Rickman et al. [31] in Equation (2).

$$
B_{r}=\frac{50}{7}(E-28 v+10.2)
$$

where $B_{r}$ is the brittleness ratio; $E$ is the Young's modulus (MPa); and $v$ is the Poisson's ratio.

Finally, the fracability index was calculated and analyzed for both EF\#5 and $\mathrm{SH} \# 5$ while using Buller et al. [32] in Equation (3).

$$
\text { Frac }_{\text {index }}=\frac{B_{r}}{T I V}
$$

where Fracindex is the fracability index; and, $B_{r}$ is the brittleness ratio defined by Rickman et al. [31] in Equation (2), while TIV is the transverse interval velocity and is defined by the following equation.

$$
T I V=\frac{D^{T S} S_{\text {slow }}}{D_{\text {TS }}}
$$

where DTS $S_{\text {slow }}$ is the slow-sonic shear travel time (s), obtained from slow sonic velocity, $\mathrm{S}_{2}(\mathrm{~m} / \mathrm{s})$ and $D T S_{\text {fast }}$ is the fast-sonic shear travel time (s), obtained from fast sonic velocity, $\mathrm{S}_{1}(\mathrm{~m} / \mathrm{s})$ [33]. 
To start the axial velocity test, core sample jacketing was done by placing the core plug inside a $\mathrm{HP}$ and elevated temperature rubber sleeve with both ultrasonic transducers (receiver and source) are in place, as shown in Figure 3.

The sample was then inserted in the HP vessel and secured. The confining pressure was applied on the sample starting at $6.89 \mathrm{MPa}$, increased up to $68.94 \mathrm{MPa}$ incrementally (6.89 MPa increment), and then decreased incrementally at the same increment down to $6.89 \mathrm{MPa}$. All of the three velocities $\left(\mathrm{P}, \mathrm{S}_{1}\right.$, and $\left.\mathrm{S}_{2}\right)$ were measured and displayed after each step of confining pressure increment (Figure 4 ).

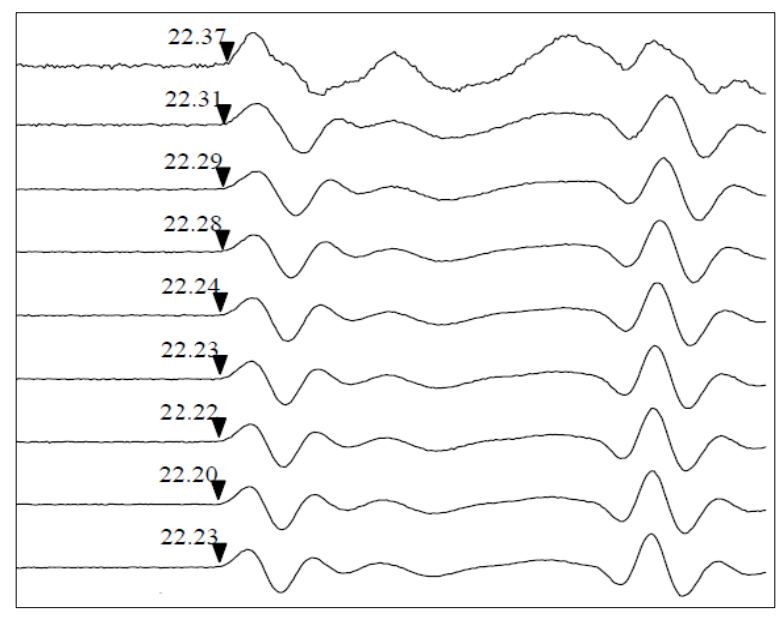

Figure 4. An example of waveforms for the $\mathrm{P}$ arrivals at different confining pressures from ultrasonic velocity test.

\subsection{Thermal Shock Experiment}

Thermal shock was applied into the core samples (EF\#5 and SH\#5) individually by injecting cold nitrogen at $-18{ }^{\circ} \mathrm{C}$ and $6.89 \mathrm{MPa}$. First, the samples were heated to reservoir temperature $\left(82^{\circ} \mathrm{C}\right)$ for $1 \mathrm{~h}$. Next, nitrogen at $-18^{\circ} \mathrm{C}$ was injected into each core sample at a pressure of $6.89 \mathrm{MPa}$ for $15 \mathrm{~min}$. The apparatus used to perform the thermal shocking technique that is composed of a Quizix pump (QX-6000, Chandler Engineering, Broken Arrow, OK, USA) with a maximum working pressure of $41 \mathrm{MPa}$, two HP stainless-steel accumulators with maximum working pressures of $103 \mathrm{MPa}$, a HP stainless steel core holder with a maximum working pressure of $103 \mathrm{MPa}$, a HP nitrogen gas cylinder, a plastic cooling bath, a high temperature heating jacket $\left(T_{\max }=115^{\circ} \mathrm{C}\right)$, hydraulic oil, insulation tape, pressure gauges, and a fresh water tank (Figure 5).

Thermal Shock Procedure

The experimental procedures are presented below:

- The core plug was placed into the core holder, and the core holder was secured and connected to the HP gas accumulator. Then, the heating jacket was turned on to heat the core to $82{ }^{\circ} \mathrm{C}$.

- The cooling bath was prepared by mixing ice with the sodium chloride $(\mathrm{NaCl})$ crystals to achieve the desired temperature $\left(-18{ }^{\circ} \mathrm{C}\right)$. Meanwhile, the temperature was measured while using a thermometer. The HP gas accumulator was then surrounded by the ice-salt cooling mixture.

- The nitrogen cylinder valve was opened to let the gas flow and accumulate in the second HP gas accumulator. Then, the gas was left in the cooling mixture for $30 \mathrm{~min}$ to reach the desirable temperature $\left(-18^{\circ} \mathrm{C}\right)$.

- After heating the core sample at the temperature of $82^{\circ} \mathrm{C}$ for $60 \mathrm{~min}$, the valve between the core holder and the second gas accumulator was opened and the core sample was subjected to the cold nitrogen for $15 \mathrm{~min}$. Meanwhile, the pump was set to deliver the water from the fresh water tank 
to the first HP accumulator, which contained the hydraulic oil till the injection pressure reached 6.89 MPa.

- The pump was turned off and the bleeding valve was opened gradually to release the pressure in the core holder.

This procedure was used for the both core samples (EF\#5 and SH\#5).

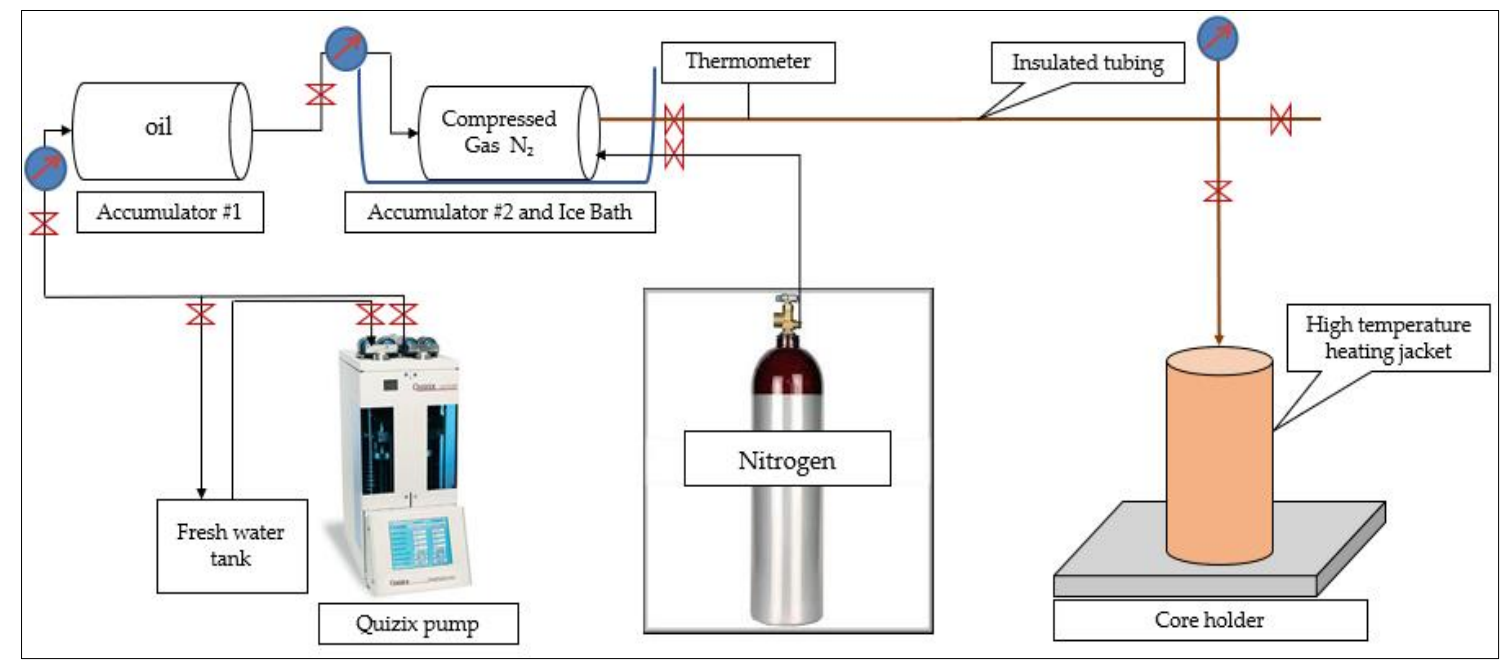

Figure 5. Schematic diagram of thermal shock technique setup.

\section{Results and Discussion}

The results that were obtained from the thermal shock tests demonstrated that cracks were created and propagated after applying thermal shock. Thermal shock not only created cracks on the core surface, but it also altered reservoir rock properties (porosity and permeability) and rock mechanical properties (Young's modulus, Poisson's ratio, and brittleness ratio).

Significant changes in P velocity were observed after conducting the thermal shocks on both EF\#5 and SH\#5 core samples, which is an indication of creating induced fractures. Also, when comparing pre-and post-thermal shock test results showed both porosity and permeability enhancement of the core samples. The thermal shock test results revealed that brittleness ratio and fracability index of both core samples were altered after conducting thermal shock cycles. Following are the results analysis for each core sample in terms of porosity, permeability, and rock mechanical properties.

\subsection{Porosity Results}

It is obvious that there was a slight increase in porosity of EF\#5 after 1st and 2nd thermal shock, which is an indication of crack growth (Table 3). Whereas, after the 3rd thermal shock, the porosity of EF\#5 decreased by $0.4 \%$, which might be a sign of crack healing.

Table 3. Porosity results of core sample EF\#5 before and after thermal shocking. TS: thermal shock; and BTS: before thermal shock.

\begin{tabular}{ccc}
\hline TS Cycles & Porosity (\%) & Percent of Increase or Decrease (\%) \\
\hline BTS & 11.95 & - \\
After 1st TS & 12.11 & +1.34 \\
After 2nd TS & 12.43 & +2.64 \\
After 3rd TS & 12.38 & -0.4 \\
\hline
\end{tabular}

The results show that porosity of SH\#5 decreased by $4.92 \%$ after completing 1 st thermal shock and increased by $14.3 \%$ after conducting 2 nd thermal shock. The third thermal shock resulted in a 
decrease in porosity by $3.01 \%$. The results are shown in Table 4 . Increase in porosity is an indication of creating new cracks or crack growth in the core sample whereas the decrease in porosity is believed to be due to the crack healing, as explained above.

Table 4. Porosity results of core sample SH\#5 before and after thermal shocking.

\begin{tabular}{ccc}
\hline TS Cycles & Porosity (\%) & Percent of Increase or Decrease (\%) \\
\hline BTS & 1.83 & - \\
After 1st TS & 1.74 & -4.92 \\
After 2nd TS & 1.99 & +14.3 \\
After 3rd TS & 1.93 & -3.01 \\
\hline
\end{tabular}

\subsection{Permeability Results}

Like porosity measurements, the permeability of the core sample was measured before and after conducting each thermal shock. As shale has ultra-low permeability, it took 3-4 days to measure the permeability using the complex transient method. Following are the permeability results of EF\#5 and $\mathrm{SH}$ 5.

After the 1st thermal shock, there was an increase in permeability of EF\#5 by $32.7 \%$ (Table 5 ). It is believed that this increase is resulted from crack growth after the hot core was exposed to cold nitrogen. After the 2nd thermal shock, a small increase in permeability was observed, indicating that there was little crack growth. After the 3rd thermal shock, it was observed that the permeability had decreased by $27.1 \%$ because of crack healing.

Table 5. Permeability results of core sample EF\#5 before and after thermal shocking.

\begin{tabular}{|c|c|c|c|c|}
\hline TS Cycles & $\begin{array}{c}\text { Confining } \\
\text { Pressure (MPa) }\end{array}$ & $\begin{array}{l}\text { Pore Pressure } \\
(\mathrm{MPa})\end{array}$ & $\begin{array}{l}\text { Permeability } \\
\qquad\left(10^{19} \mathrm{~m}^{2}\right)\end{array}$ & $\begin{array}{c}\text { Percent of Increase or } \\
\text { Decrease }(\%)\end{array}$ \\
\hline BTS & \multirow{4}{*}{13.79} & \multirow{4}{*}{6.89} & 4.18 & - \\
\hline After 1st TS & & & 5.55 & +32.7 \\
\hline After 2nd TS & & & 6.52 & +17.4 \\
\hline After 3rd TS & & & 4.75 & -27.1 \\
\hline
\end{tabular}

There was a significant improvement in the permeability of SH\#5 after the 2nd thermal shock (Table 6). The percent increase of permeability after the second cycle of thermal shock is $920 \%$, which is an indication of creating a highly induced fracture in the core sample. On the other hand, the 3rd thermal shock had a reverse effect where the permeability decreased by $96.5 \%$ as compared to its initial value. It is believed that this reduction in permeability caused by high crack healing.

Table 6. Permeability results of core sample SH\#5 before and after thermal shocking.

\begin{tabular}{|c|c|c|c|c|}
\hline TS Cycles & $\begin{array}{c}\text { Confining } \\
\text { Pressure (MPa) }\end{array}$ & $\begin{array}{l}\text { Pore Pressure } \\
\text { (MPa) }\end{array}$ & $\begin{array}{l}\text { Permeability } \\
\quad\left(10^{19} \mathrm{~m}^{2}\right)\end{array}$ & $\begin{array}{c}\text { Percent of Increase or } \\
\text { Decrease }(\%)\end{array}$ \\
\hline BTS & & & 5.19 & - \\
\hline After 1st TS & & & 4.19 & -19.2 \\
\hline After 2nd TS & 13.79 & 6.89 & 42.80 & +920 \\
\hline After 3rd TS & & & 1.47 & -96.5 \\
\hline
\end{tabular}

\subsection{Axial Velocity Test Results}

Ultrasonic velocity measurement is used to detect fractures in a rock sample by measuring the P-wave and S-wave velocities. P-wave velocity, Young's modulus, Poisson's ratio, rock brittleness, and fracability index results are presented for each core sample individually before and after each thermal shock experiment. 
P-wave velocity results of (EF\#5) are presented in Figure 6. It is obvious that there is a direct relationship between the P-velocity and the confining pressure, owing to more compaction at higher confining pressures, which results in faster arrival of the P-wave. Also, the results demonstrate P-velocity alteration after conducting thermal shock technique. After performing the first thermal shock the P-velocity decreased at high confining pressures, which is an indication of induced cracks. Figure 7 presents the condition of core sample EF\#5 before and after the thermal shocks.

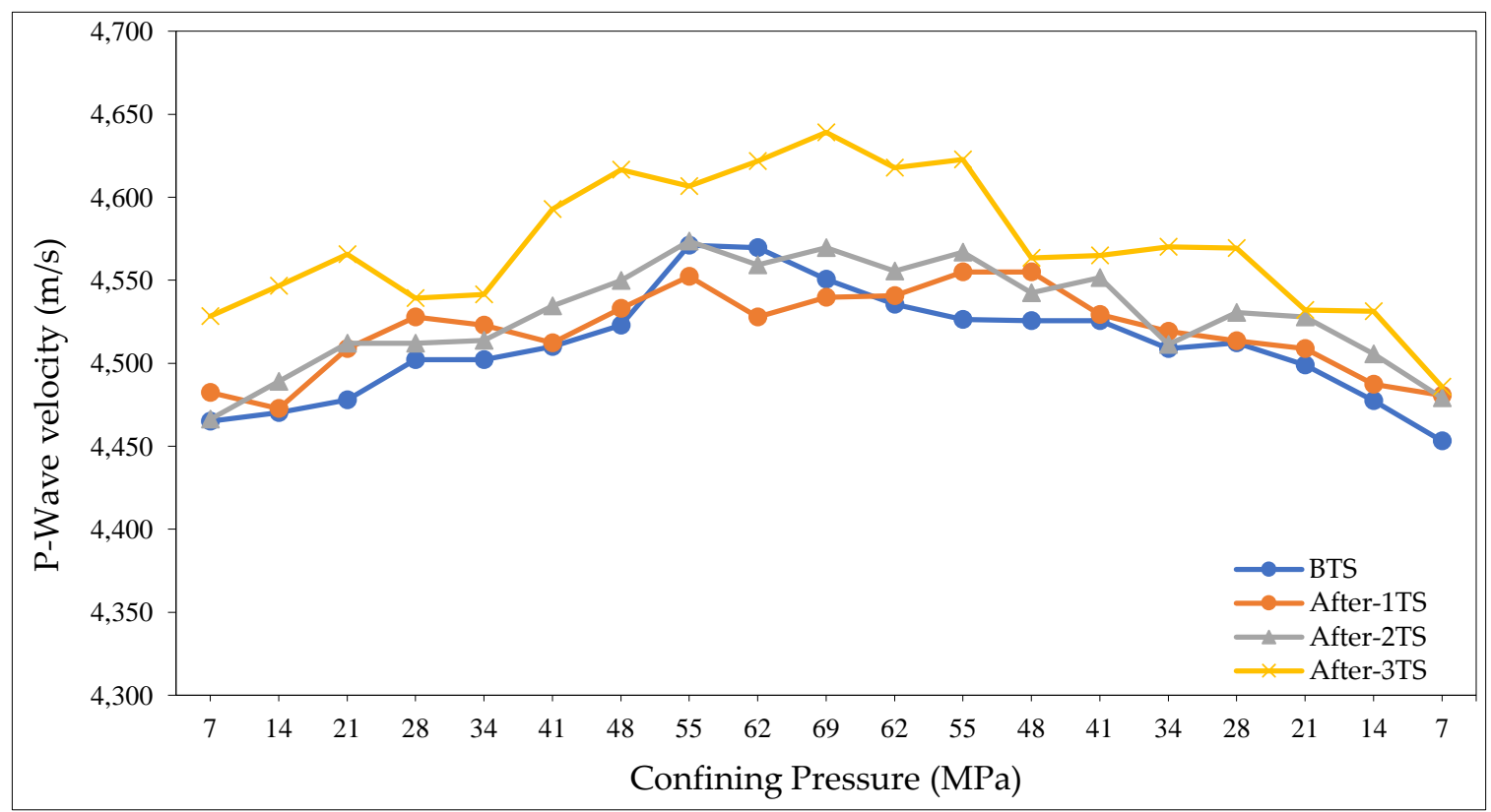

Figure 6. P-wave velocity results of EF\#5 at different confining pressures before and after thermal shock.

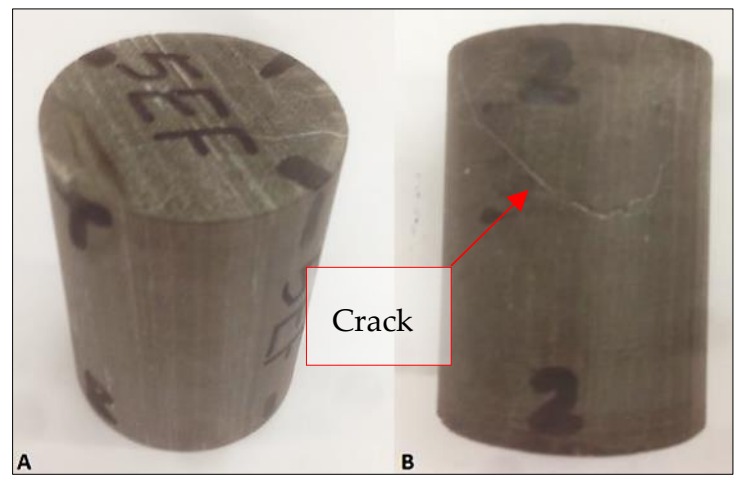

Figure 7. Core sample EF\#5 (A) BTS and (B) after 3rd thermal shock.

Young's modulus and Poisson's ratio results of EF\#5 are presented in Figure 8a. There is a direct relationship between Young's modulus and confining pressure. Additionally, performing thermal shock on the core sample also altered Young's modulus of the core sample. For instance, at $68.94 \mathrm{MPa}$ confining pressure, Young's modulus was $37.8 \mathrm{GPa}$ after completing 1st thermal shock, whereas it was 36.9 GPa before conducting thermal shock. 


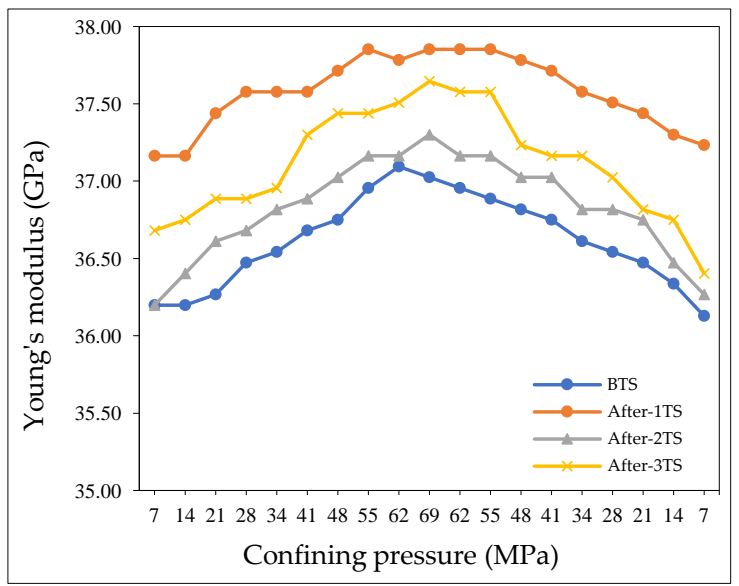

(a)

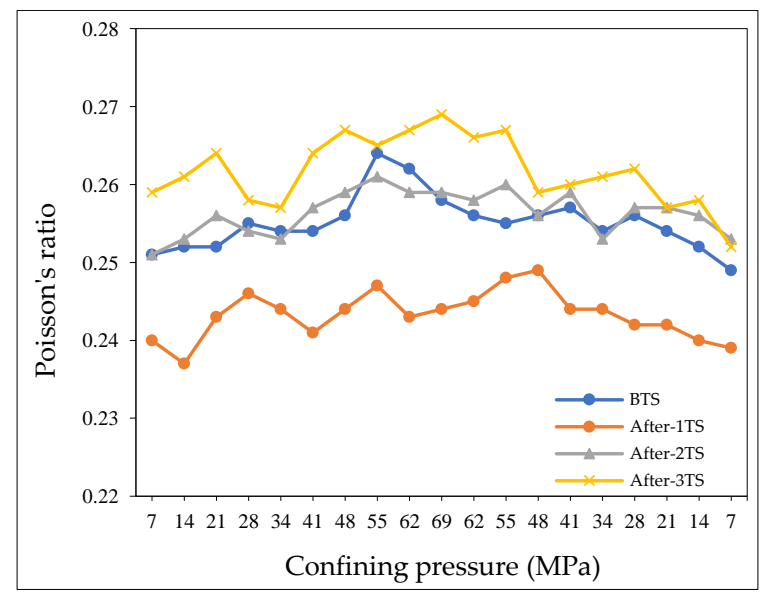

(b)

Figure 8. (a) Young's modulus results of EF\#5 at different confining pressures before and after thermal shock; and (b) Poisson's ratio results of EF\#5 at different confining pressures before and after thermal shock.

Thermal shock not only altered the Young's modulus, but also affected the Poisson's ratio. It can be seen in Figure $8 \mathrm{~b}$ that first thermal shock reduced EF\#5 Poisson's ratio, while both second and third shocks increased it.

Effects of thermal shock on brittleness ratio of the core sample EF\#5 were investigated. Figure 9a shows the effect of thermal shock on EF\#5 where the core became more brittle after the 1st thermal shock. It is obvious that the 1st thermal shock increased the core sample brittleness ratio from about 60 to about 62 , while both second and third thermal shocks did not clearly alter the rock brittleness ratio.

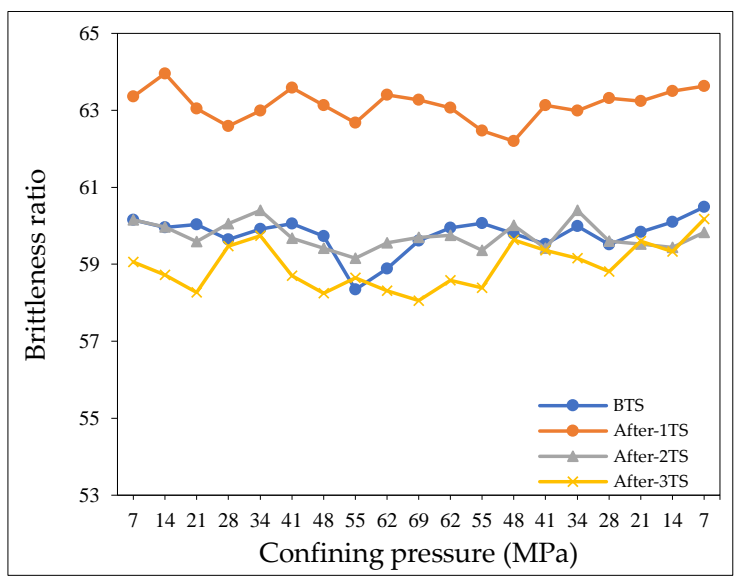

(a)

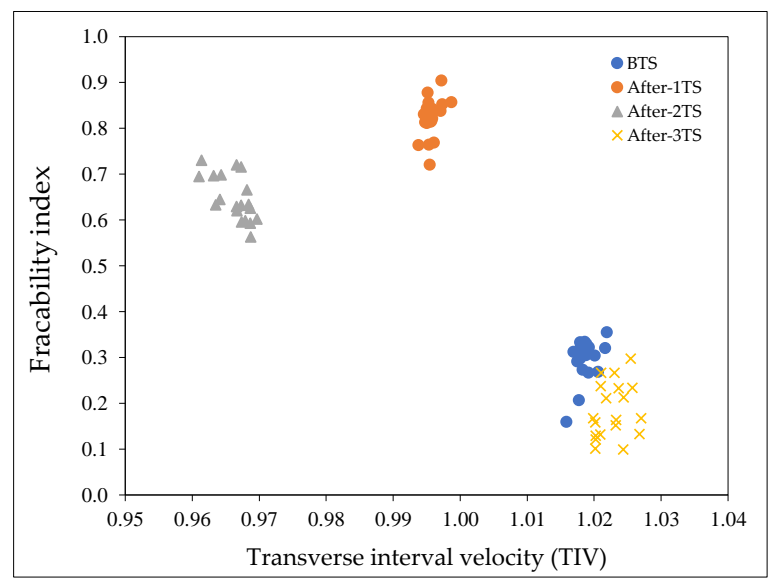

(b)

Figure 9. (a) Brittleness ratio results of EF\#5 at different confining pressures before and after thermal shock; and (b) fracability index of EF\#5 vs. transverse interval velocity (TIV) before and after thermal shock.

As previously explained, the fracability index is the ratio between the brittleness ratio and the transverse interval velocity defined by Buller et al. [32] (see Equation (3)) The results show that EF\#5 has the highest fracability index after completing the 1st thermal shock (Figure $9 \mathrm{~b}$ ). The fracability index increased by between 0.2 and 0.8 .

It is obvious that there is a direct relationship between the P-wave velocity of $\mathrm{SH \# 5}$ and the confining pressure owing to higher rock compaction (Figure 10). It can also be observed that thermal shock altered P-wave velocity after both the second and third cycles, while the first cycle has 
insignificant effect on $V_{p}$. This reduction in $V_{p}$ is an evidence of creating new fractures. Figure 11 presents the condition of core sample SH\#5 before and after the thermal shock, in which the induced fractures after 2nd and 3rd thermal shocks are clear.

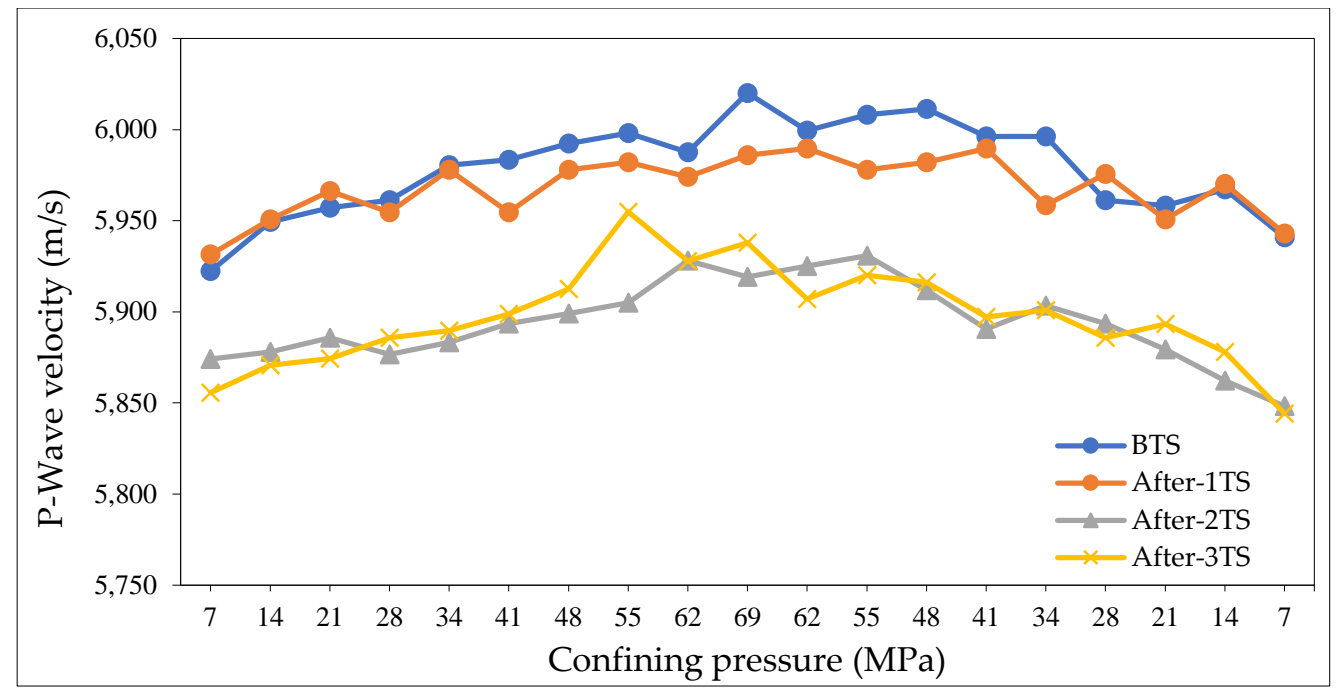

Figure 10. P-wave velocity results of $\mathrm{SH \# 5}$ at different confining pressures before and after thermal shock.

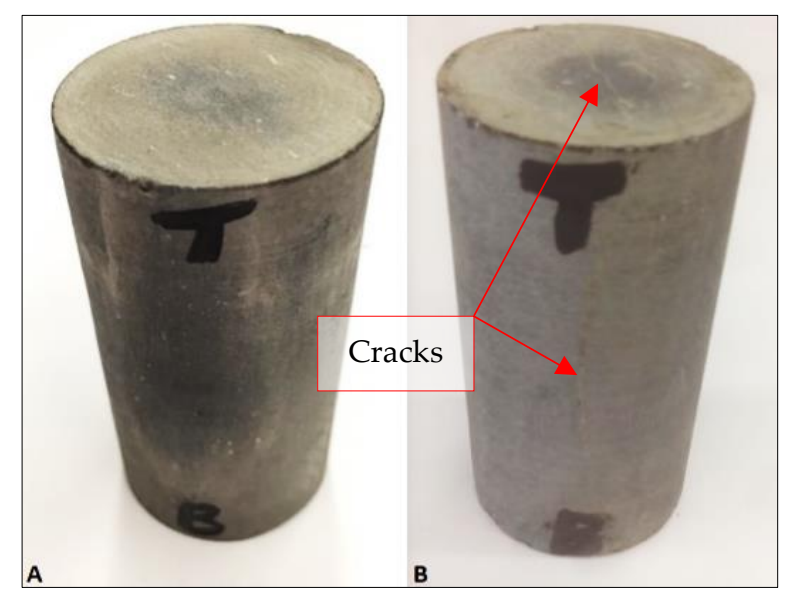

Figure 11. Core sample SH\#5 (A) BTS; and (B) after 2nd thermal shock.

There is a direct relationship between Young's modulus of SH\#5 and confining pressure (Figure 12a). Unlike core sample EF\#5, thermal shock cycles reduced the Young's modulus of SH\#5. Thermal shock not only altered the Young's modulus, but it also affected the Poisson's ratio of the core sample. It is clear that Poisson's ratio decreased to an average of 0.29 after the 2nd thermal shock, while 1st and 3rd thermal shock had small effects on it (Figure 12b).

It is also obvious that the core became more brittle after the 2nd thermal shock, whereas the 1st and 3rd thermal shock had an adverse effect on brittleness ratio (Figure 13a). The brittleness ratio of SH\#5 increased by between 2 and 4 . 


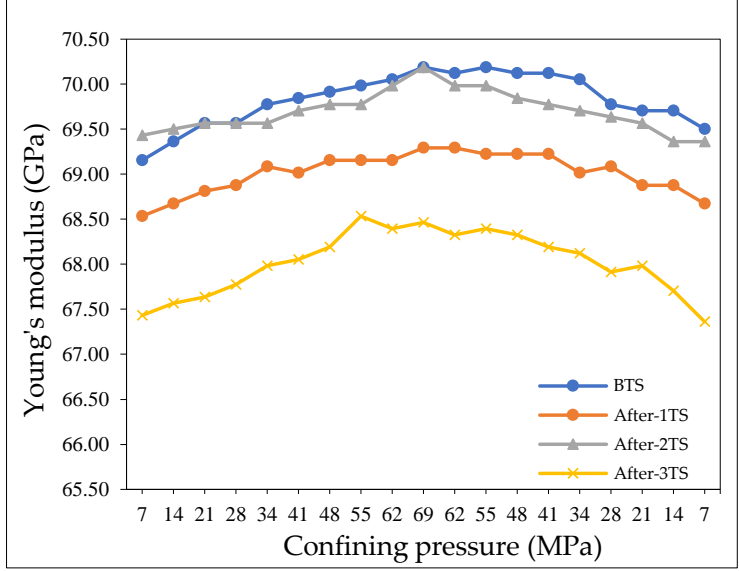

(a)

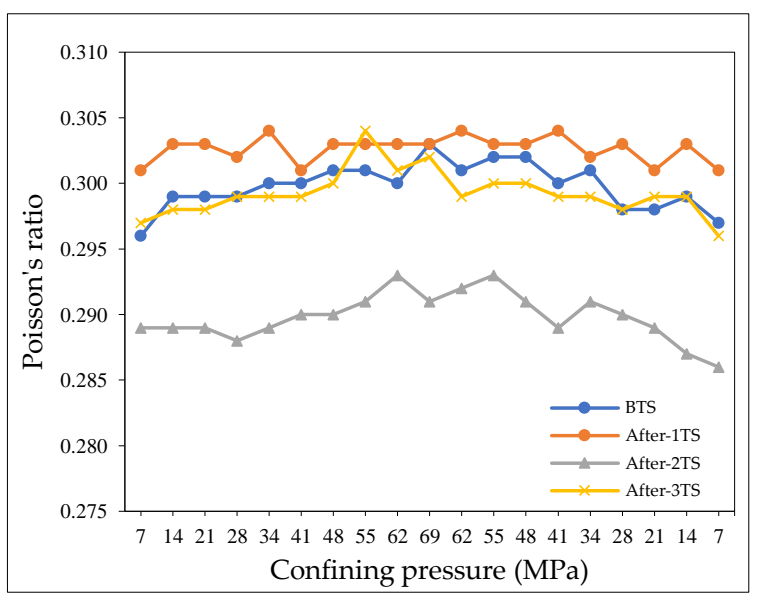

(b)

Figure 12. (a) Young's modulus results of SH\#5 at different confining pressures before and after thermal shock; and (b) Poisson's ratio results of SH\#5 at different confining pressures before and after thermal shock.

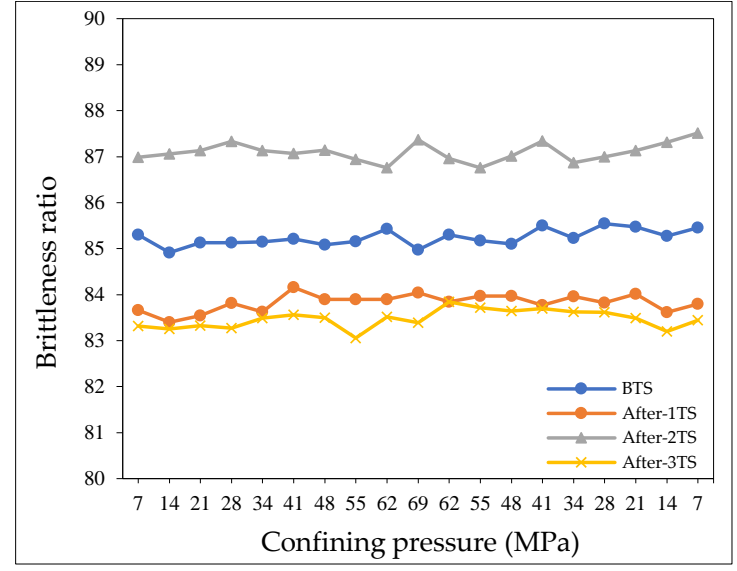

(a)

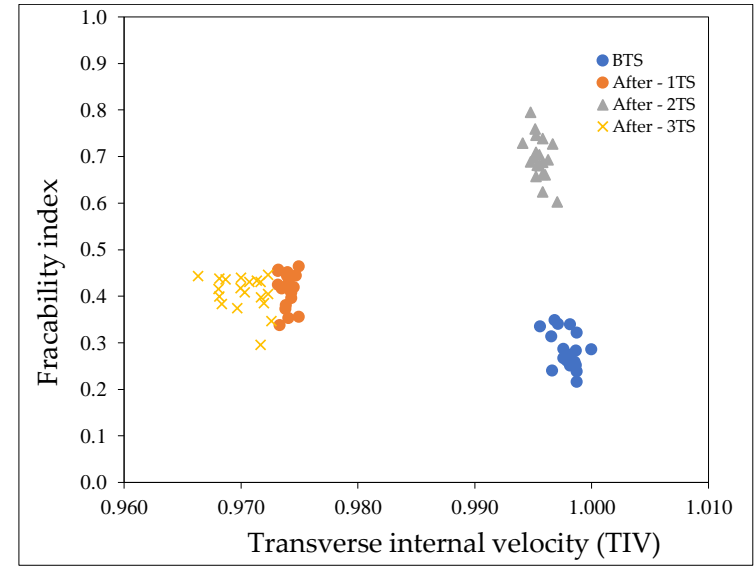

(b)

Figure 13. (a) Brittleness ratio results of $\mathrm{SH \# 5}$ at different confining pressures before and after thermal shock; and (b) fracability Index of SH\#5 vs. transverse internal velocity (TIV) before and after thermal shock.

Unlike 1st and 3rd thermal shock, the results show that the 2nd thermal shock clearly increased the SH\#5 fracability index (Figure 13b). After the 2nd thermal shock, TIV was approximately the same as before thermal shock (BTS) (0.1) and the fracability index increased by about 0.6 . Whereas, 1 st and 3rd thermal shock increased the fracability index by about 0.2 .

\section{Conclusions}

Research has shown that cryogenic fracturing (thermal shocking with cold fluid) could be an alternative to the traditional hydraulic fracturing of unconventional reservoirs, in which water-based fluids are used. However, previous studies on thermal shocking have generally examined only a few parameters at a time. To provide a more complete overview of the process, this study examined the effects of thermal shocking with low-temperature nitrogen gas on the porosities, permeabilities, and rock mechanical properties of unconventional reservoirs. 
- The results strongly suggest that the thermal shocking produced cracks. The porosity increased by between $1.34 \%$ and $14.3 \%$, the permeability increased by between $17.4 \%$ and $920 \%$, and the average P-wave velocity decreased by up to $100 \mathrm{~m} / \mathrm{s}$.

- Young's modulus increased by between $0.5 \mathrm{GPa}$ and $2 \mathrm{GPa}$, and the poison's ratio decreased by between 0.01 and 0.02 .

- From the reduction in P-wave velocity and the changes in Young's modulus and Poison's ratio, it was determined that the brittleness ratio increased by between 2 and 4 and the fracability index increased by between 0.2 and 0.8 .

- Optimum number of thermal shock cycles varies from one formation to another, depending on the mineralogy and rock type. The results showed that EF\#5 became more brittle after 1st thermal shock, whereas brittleness of SH\#5 increased after completing the second thermal shock.

- The results of this experimental study demonstrated that thermal shock technique may be used as an effective method to enhance the porosities and permeabilities of unconventional reservoirs, and thus minimize formation damage.

- Cryogenic fracturing (thermal shocking with cold fluid) could be used in the future to improve oil/gas recovery from unconventional reservoirs.

Author Contributions: K.E. built the experimental setup, performed the experimental work and wrote the manuscript. H.E. developed the idea of the research, supervised the research, and revised the manuscript.

Funding: This research received no external funding.

Conflicts of Interest: The authors declare no conflict of interest.

\section{References}

1. Gutierrez, G.; Ramirez, L.; Sierra, J.R.; Medina, E.; Gutierrez, L.J.; Salguero, J. Improvements in Multistage Fracturing, Remolino Field, Mexico. In Proceedings of the SPE Hydraulic Fracturing Technology Conference, The Woodlands, TX, USA, 4-6 February 2014.

2. Janszen, M.; Bakker, T.; Zitha, P.L.J. Hydraulic Fracturing in the Dutch Posedonia Shale. In Proceedings of the SPE European Formation Damage Conference and Exhibition, Budapest, Hungary, 3-5 June 2015.

3. Ajayi, B.T.; Walker, K.J.; Wutherich, K.; Sink, J. Channel Hydraulic Fracturing and Its Applicability in the Marcellus Shale. In Proceedings of the SPE Eastern Regional Meeting, Columbus, OH, USA, 17-19 August 2011.

4. Morsy, S.; Sheng, J.J; Soliman, M.Y. Improving Hydraulic Fracturing of Shale Formations by Acidizing. In Proceedings of the SPE Eastern Regional Meeting, Pittsburgh, PA, USA, 20-22 August 2013.

5. Morsy, S.; Gomaa, A.; Sheng, J.J. Improvement of Eagle Ford Shale Formations Water Imbibition by Mineral Dissolution and Wettability Alteration. In Proceedings of the SPE Unconventional Resources Conference, The Woodlands, TX, USA, 1-3 April 2014.

6. Finnie, I.; Cooper, J.; Berlie, J. Fracture Propagation in Rock by Transient Cooling. Int. J. Rock Mech. Min. Sci. 1979, 16, 11-21. [CrossRef]

7. Geyer, J.F.; Nemat-Nasser, S. Experimental Investigation of Thermally Induced Interacting Cracks in Brittle Solids. Int. J. Solids Struct. 1982, 18, 349-356. [CrossRef]

8. Grundmann, S.; Rodvelt, G.; Dials, G.; Allen, R. Cryogenic Nitrogen as a Hydraulic Fracturing Fluid in the Devonian Shale. In Proceedings of the SPE Eastern Regional Meeting, Pittsburgh, PA, USA, 9-11 November 1998.

9. Kim, K.; Kemeny, J. Effect of Thermal Shock and Rapid Unloading on Mechanical Rock Properties. In Proceedings of the 43rd U.S. Rock Mechanics Symposium, Asheville, NC, USA, 28 June-1 July 2009.

10. Kocabas, I. An Analytical Model of Temperature and Stress Fields During Cold-Water Injection into an Oil Reservoir. In Proceedings of the SPE International Conference and Exhibition, Abu Dhabi, UAE, 10-13 October 2004.

11. Tarasovs, S.; Ghassemi, A. Propagation of a System of Cracks Under Thermal Stress. In Proceedings of the 45th U.S. Rock Mechanics/Geomechanics Symposium, San Francisco, CA, USA, 26-29 June 2011. 
12. Kumar, D.; Gutierrez, M. Effects of Temperature on Two-Dimensional Hydraulic Fracturing in Impermeable Rocks. In Proceedings of the 45th U.S. Rock Mechanics/Geomechanics Symposium, San Francisco, CA, USA, 26-29 June 2011.

13. Tran, D.; Settari, A.; Nghiem, L. Initiation and Propagation of Secondary Cracks in Thermo-Poroelastic Media. In Proceedings of the 46th U.S. Rock Mechanics/Geomechanics Symposium, Chicago, IL, USA, 24-27 June 2012.

14. Alqahtani, N. Experimental Study and Finite Element Modeling of Cryogenic Fracturing in Unconventional Reservoirs. Ph.D. Thesis, Colorado School of Mines, Golden, CO, USA, 2015.

15. Zhao, B.; Zhang, G.; Lin, Q. The Application of Cryogenic Treatment during Refracture Process-Laboratory Studies. In Proceedings of the 50th U.S. Rock Mechanics/Geomechanics Symposium, Houston, TX, USA, 26-29 June 2016.

16. Yao, B.; Wang, L.; Patterson, T.; Kneafsey, T.J.; Yin, X.; Wu, Y. Experimental Study and Modeling of Cryogenic Fracturing Treatment of Synthetic Rock Samples Using Liquid Nitrogen under Tri-Axial Stresses. In Proceedings of the SPE Unconventional Resources Conference, Calgary, AB, Canada, 15-16 February 2017.

17. Carpenter, C. Cryogenic-Fracturing Treatment of Synthetic-Rock with Liquid Nitrogen. J. Pet. Technol. 2017, 69, 70-71. [CrossRef]

18. Cha, M.; Alqahtani, N.B.; Yao, B.; Yin, X.; Kneafsey, T.J.; Wang, L.; Miskimins, J.L. Cryogenic Fracturing of Wellbores Under True Triaxial-Confining Stresses: Experimental Investigation. SPE J. 2018. [CrossRef]

19. Wang, L.; Yao, B.; Cha, M.; Alqahtani, N.B.; Patterson, T.W.; Kneafsey, T.J.; Miskimins, J.L.; Yin, X.; Wu, Y.S. Waterless Fracturing Technologies for Unconventional Reservoirs-Opportunities for Liquid Nitrogen. J. Nat. Gas Sci. Eng. 2016, 35, 160-174. [CrossRef]

20. Smith, D. Methods and Apparatus to Enhance Oil Recovery in Wells. Available online: https://patents. google.com/patent/US8490696B2/en (accessed on 15 January 2014).

21. Kemeny, J.; Apted, M.; Martin, D. Rockfall at Yucca Mountain due to Thermal, Seismic and Time-Dependance. In Proceedings of the 11th International High Level Radioactive Waste Management, Las Vegas, NV, USA, 30 April-4 May 2006.

22. Glamheden, R.; Lindblom, U. Thermal and Mechanical Behavior of Refrigerated Caverns in Hard Rock. Tunn. Undergr. Space Technol. 2002, 17, 341-353. [CrossRef]

23. Bellopede, R.; Ferrero, A.; Manfredotti, L.; Marini, P.; Migliazza, M. The Effect of Thermal Stresses on the Mechanical Behavior of Natural Building Stones. In Fracture and Failure of Natural Building Stones; Springer: Dordrecht, The Netherlands, 2006; pp. 397-425, ISBN 978-1-4020-5077-0.

24. Yavuz, H.; Altindag, R.; Sarac, S.; Ugur, I.; Sengun, N. Estimating the Index Properties of Deteriorated Carbonate Rocks due to Freeze-Thaw and Thermal Shock Weathering. Int. J. Rock Mech. Min. Sci. 2006, 43, 767-775. [CrossRef]

25. Kingery, W.D. Factors Affecting Thermal Stress Resistance of Ceramic Materials. J. Am. Ceram. Soc. 1955, 38, 3-15. [CrossRef]

26. Kim, K.M.; Kemeny, J. Effect of Thermal Loading on Compressional Wave Velocity, Mode I Fracture Toughness and Tensile Strength. In Proceedings of the 42nd U.S. Rock Mechanics Symposium, San Francisco, CA, USA, 29 June-2 July 2008.

27. Enayatpour, S.; Patzek, T. Thermal Shock in Reservoir Rock Enhances the Hydraulic Fracturing of Gas Shales. In Proceedings of the Unconventional Resources Technology Conference, Denver, CO, USA, 12-14 August 2013.

28. Wang, X.; Schubnel, A.; Fortin, J.; Guéguen, Y.; Ge, H. Physical Properties and Brittle Strength of Thermally Cracked Granite Under Confinement. J. Geophys. Res. Solid Earth 2013, 118, 6099-6112. [CrossRef]

29. Bai, M. Why Are Brittleness and Fracability Not Equivalent In Designing Hydraulic Fracturing In Tight Shale Gas Reservoirs. Petroleum 2016, 2, 1-19. [CrossRef]

30. Boitnott, G.N. Use of Complex Pore Pressure Transients to Measure Permeability of Rocks. In Proceedings of the SPE Annual Technical Conference and Exhibition, San Antonio, TX, USA, 5-8 October 1997.

31. Rickman, R.; Mullen, M.; Petre, E.; Grieser, B.; Kundert, D. A Practical Use of Shale Petrophysics for Stimulation Design Optimization: All Shale Plays Are Not Clones of the Barnett Shale. In Proceedings of the SPE Annual Technical Conference and Exhibition, Denver, CO, USA, 21-24 September 2008. 
32. Buller, D.; Hughes, S.; Market, J.; Petre, E.; Spain, D.; Odumosu, T. Petrophysical Evaluation for Enhancing Hydraulic Stimulation in Horizontal Shale Gas Wells. In Proceedings of the SPE Annual Technical Conference and Exhibition, Florence, Italy, 19-22 September 2010.

33. Hardage, B. Fracture Identification and Evaluation Using S Waves. Available online: http://www. searchanddiscovery.com/documents/2011/40792hardage/images/hardage (accessed on 15 August 2011). 